\title{
FINDING LASTING SOLUTIONS TO THE EARLY DETERIORATION OF CONSTRUCTED ROADS IN NIGERIA
}

\author{
H. A. Ahmadu 1 , *, A. O. Abdulyekeen ${ }^{2}$, A. K. Alade ${ }^{3}$ and A. Yusuf ${ }^{4}$ \\ $\mathbf{1 , 2 , 3 , 4}$, DEPARTMENT OF SURVEYING AND GEOINFORMATICS, UNIVERSITY OF ILORIN, KWARA STATE, NIGERIA \\ Email addresses: ${ }^{1}$ husseinahmadu@yahoo.com , 2 abdulyekeen.ao@unilorin.edu.ng, \\ 3 alade_azeez@yahoo.com, 4 yusganol@gmail.com
}

\begin{abstract}
The socioeconomic benefits of having good roads is hardly realized in most developing countries, due to the fact that most constructed roads tend to deteriorate very rapidly before their expected life span. Several factors have been identified by different researchers to be the cause of this problem. This paper tried to find solutions to some of these factors using three phases of route survey and design of roadways, namely; route location, data acquisition, and geometric design. The results showed that most of the factors that facilitate early deterioration of constructed roads could be solved through the processes involved in the three phases of route survey and design of roadways. The paper concluded that route survey and design of roadways thoroughly addresses and solves most of the factors that facilitate early deterioration of constructed roads.
\end{abstract}

\section{Keywords: Route survey, Route location, Data acquisition, Geometric design, Roadway deterioration}

\section{INTRODUCTION}

Roadways are known to be one of the cheapest and commonest means of transportation in the world. Apart from being cheap, their invaluable importance to the Socio-economic development of the society cannot be over emphasized. Roadways are known to provide an enabling medium for improving the condition of rural areas, thereby leading to urbanization and a reduction in poverty level. Roadways are particularly beneficial to the society, as they provide access to state services such as Health, Education, Agricultural extension and provision of information. Roads are a source of wellbeing, bringing people together from a small village to a large city $[1$, 2].

However, in most developing countries including Nigeria, most of the socio-economic benefits of having good roads is hardly realized, due to the fact that most constructed roads tend to deteriorate very rapidly, resulting into very high cost of repairs, rehabilitation and maintenance by federal road maintenance agencies.

Akinyede [3], attributed this problem (early deterioration of constructed roads) to poor route selection. He noted that an effective appraisal of the terrain is needed to select routes which allow for good road condition at the lowest possible cost. According to [4], poor design and construction are factors that contributes to the early deterioration of constructed roads. Toryila [5], identified poor drainage as a major factor that causes early deterioration of roadways. He concluded that in order to avoid early deterioration of roadways, and enhance its performance, it is necessary to provide adequate drainages for the roadway.

Other factors including; poor maintenance of already built roads, use of low-quality materials in construction of roads, climate change, plying of heavy traffic on roads that were not designed to accommodate such traffic, have been identified by researchers [6-8].

The purpose of this paper is to find lasting solutions to factors that cause early deterioration of constructed roads in Nigeria. Route survey and design of a proposed road in Zaria, Kaduna state, Nigeria was used as a case study.

\section{LITERATURE REVIEW}

Roadway deterioration and pavement failures in Nigeria have been reported in several research works, such as the works of $[4,6,8]$. 
Ogundipe [6], investigated road pavement failure along Aramoko - Ilesa highway, which he noted was caused by poor soil properties. Osuolale, et. al [8], investigated highway pavement failure along Ibadan Iseyin road, and they concluded that poor maintenance and poor drainages were the causes of pavement failures. Afolayan and Abidoye [10] investigated causes failures on Nigerian roads. They identified several factors to be the cause, such as poor design, inadequate preliminary geological investigation, lack of periodic and routine maintenance, bad drainage, improper use and overloading. Odunfa and Owolabi [11], studied the effect of moisture content on pavement failure along Lagos-Ibadan express way. They examined the effect of moisture on geotechnical parameters of a roadway, and their work concluded that inadequate moisture in pavement materials was a factor that cause pavement failure.

However, very little has been done in trying to find solutions to the problem of early roadway deterioration and pavement failure in Nigeria. The works of [3], suggested an effective appraisal of the terrain for route selection, while [10] tried to proffer solutions to this problem, which include; provision of adequate and appropriate design, supervision and quality control, decongestion of the Nigerian roads, and timely maintenance.

\section{METHODOLOGY}

Three phases of route survey and design of roadways were used to address some of the factors that facilitate early deterioration of constructed roads. These phases include; Route location, data acquisition, and geometric design. This approach was applied to a proposed roadway from Bassawa to Angwan Abashi, located in Zaria, Kaduna state - Nigeria, which served as a case study for this paper.

\subsection{Route Location}

Route location has been identified by [3], as one of the factors which if not properly done, can lead to early deterioration of constructed roads. Being one of the phases that must be carried out in any route survey and design of roadways, it implies that one of the solutions to the early deterioration of roadways is to have a proper route survey and design of the proposed road before it is constructed.

In this paper, a concise method of route location was adopted. A Reconnaissance survey was first carried out, during which the site was visited and a general observation of the area was made, while taking note of all the possible routes that could be selected. Samples of the soil was taken for testing, and coordinates of features along the possible routes were taken with a handheld GPS. The nature of the vegetation, land use, and drainage patterns of the area were taken note of. All the information acquired during the reconnaissance survey was represented on a reconnaissance diagram.

The second stage of the route location process was the office location, during which a satellite imagery of the study area was used in combination with the reconnaissance diagram to select the best and most economical route.

The final stage of the route location was the field location, during which the site was visited, and the route that was selected in the office was physically identified on the ground. A final detailing of features along the selected route was made with a handheld GPS.

\subsection{Data Acquisition}

The data acquisition phase contributes to solving the problem of in-appropriate design, due to the fact that the quality of data acquired from the field affects the quality of design that can be obtained in the geometric design phase. Thus, data acquisition must be properly carried out, so that design plans match the actual field conditions.

I $\mathrm{n}$ this paper two types of data were acquired during the data acquisition phase. They are the design data which comprised of $X, Y, Z$, coordinates of chainage points, and a traffic data of the area.

The design data was acquired with a Sokkia Total Station. The Total station was setup on the already established benchmarks along the selected route, and used to acquire the $X, Y, Z$, coordinates of chainage points at $25 \mathrm{~m}$ intervals, longitudinally along the center line of the selected route, and at $5 \mathrm{~m}$ intervals, covering a swath width of $20 \mathrm{~m}$ on both sides, at crosssections to the centerline of the selected route (along perpendiculars to the centerline of the selected route). The second data that was acquired was a traffic data. Although there was no past traffic count for the area, a rough estimate was made by observing the nature and volume of traffic along roads surrounding project area. A careful consideration for any possible future development of the area was also made. 


\subsection{Geometric Design}

The Geometric design phase was used to address the problem of in-appropriate design. It takes care of the design of all roadway components such as alignment (horizontal and vertical), grades, lane and shoulder widths, right of way, and design speed according to standard design specifications, laid down by roadway design and construction authorities such as American Association of State Highway and Transport Officials (AASHTO) and United States department of transport Federal Highway Administration (USDOTFHWA) [12]. As pointed out by [12], good geometric design of roadways gives provision for good drainages, erosion control facilities, slope, adequate space for sign erection, and potential for proper maintenance of the roadway after construction. This implies that most of the factors that facilitate early deterioration of roadways (poor drainages, poor maintenance) can be solved at the geometric design phase.

In this paper, design standards and specifications specified by AASHTO were used.

The geometric design was carried out using AutoCAD Land Desktop Companion, 2009. The following steps explains how the geometric design was carried out

\subsubsection{Step1: Plotting}

The $X, Y$, and $Z$ coordinates of chainage points obtained from the data acquisition stage, were imported into the AutoCAD environment via the import/export menu of the AutoCAD software. This served as the basis for the geometric design.

\subsubsection{Step2: Geometric Design of roadway components}

Several results are usually obtained from the geometric design phase, which are required for the proper setting out and construction of the proposed roadway. These results include; the horizontal tangent setting out data, horizontal curve setting out data, vertical curve setting out data, grades setting out data, plan, profile and cross-section sheets, area and volumes of cut and fill.

\subsubsection{Design Speed}

The proposed roadway was functionally classified as a primary arterial, since from its location, it would distribute traffic from a principal arterial, and bring users closer to the vicinity of their destination. Due to the classification of the road as a primary arterial, and based on the fact that the terrain of the area is a rolling and mountainous terrain, a moderate design speed of $30 \mathrm{~km} / \mathrm{h}$ was chosen as the design speed.

\subsubsection{Alignment}

In any road design and construction, two types of alignment are usually carried out. They are the horizontal alignment and the vertical alignment.

\subsection{Horizontal Alignment}

Horizontal alignment deals with the directional transition of a roadway in a horizontal plane [12]. In this paper, the horizontal alignment design was represented in the plan view. It involves the creation of tangents and the use of simple circular curves to provide directional transition between the tangents. After the curves had been created and inserted between the tangents, the centerline of the road was defined to form an alignment that can be recognized by the AutoCAD software for further operations.

\subsection{Creation of Offsets}

After the horizontal alignment was completed, offsets were created at perpendicular distances from the centerline, to define basic components of the roadway. This was done through the 'create offset' command from the alignment menu of the AutoCAD software. The following offsets were created;

\subsection{1 End of Pavement (EOP)}

The paved area of a roadway is the portion of the roadway for the movement of vehicles. It is also known as the traveled way [13]. The end of pavement is usually defined by the lane width. A standard lane width of $12 \mathrm{ft}(3.6 \mathrm{~m})$ specified by [13] for minor arterial roads was used for this research. This implies an offset distance of $3.6 \mathrm{~m}$ left and right from the centerline.

\subsection{2 End of Shoulders (EOS)}

A standard shoulder width of $4 \mathrm{ft}(1.2 \mathrm{~m})$ specified by [13] for minor arterial roads was used for this paper. Thus, the shoulder widths were measured from the centerline by offsetting a total distance of $4.8 \mathrm{~m} \mathrm{(3.6+}$ 1.2 ) to the left and right.

\subsection{Right of Way (ROW)}

A sufficient distance $20 \mathrm{~m}$ left and right of the centerline was specified as right of way (ROW) for this paper. This sufficiently accommodated all the road facilities such as the paved road, shoulders, sidewalks, and drainages. 


\subsection{Vertical Alignment}

A good vertical alignment ensures proper roadway drainages and an acceptable level of safety [12]. In this paper, the vertical alignment was represented in the profile view, with the application of suitable vertical curves to smoothen the changes in gradients of the tangents. The steps and procedures used for the vertical alignment are as follows:

\subsection{Plotting the Profile}

The profile (existing ground centerline) was plotted through the profile menu of the AutoCAD software. All the necessary profile sampling settings including scale and datum settings were made before the profile was plotted.

\subsection{Designing the Profile (Formation ground centerline)}

The profile was designed using series of straight lines known as vertical tangents. Thus, the vertical tangents were used to define the slope of the roadway.

The vertical tangents were designed to follow the existing ground terrain, in order to have an economical and efficient design. At points were the roadway crossed a waterway, sufficient clearance and cover for the construction of culverts and other components of the drainage system were made.
Vertical curves were used at points where two tangents met (change of gradient), to smoothen the transition between them.

\subsubsection{Cross-sections}

Cross-sections were generated through the crosssection menu of the AutoCAD software, by sampling the existing ground profile from the surface.

The cross-sectional plots showed cross-sections of the existing ground surface, and their corresponding finished ground surface.

\section{RESULTS AND DISCUSSION 4.1 Results}

The three phases of route survey and design solved some of the factors of pavement deterioration (reported in Table 1). The geometric design phase of the proposed route used as a case study for this research produced several results which include; horizontal tangent data (reported in Table 2), horizontal curve setting out data (reported in Table 3), vertical curve setting out data (reported in Table 4), and gradient data (reported in Table 5). The geometric design phase of the proposed road used as a case study for this paper produced the following results:

Table 1: Factors of pavement deterioration being solved at each phase of route survey and design.

\begin{tabular}{cll}
\hline S/N & Phases of Route Survey and design & Factors of Road pavement deterioration been solved \\
\hline 1 & Route Location & Poor Route selection \\
2 & Data acquisition & Poor/Inappropriate design \\
& & Poor/inappropriate Design \\
3 & Geometric design phase & Poor Drainages \\
& & Poor Maintenance \\
\hline
\end{tabular}

Table 2: Horizontal Tangent data

\begin{tabular}{cccc}
\hline $\mathrm{S} / \mathrm{N}$ & Chainage & Length of Tangent & Bearing \\
\hline 1 & $0+00$ to $1+293.01$ & 1233.01 & $92^{\circ} 36^{\prime} 49^{\prime \prime}$ \\
2 & $1+393.01$ to $2+842.74$ & 1449.74 & $23^{\circ} 56^{\prime} 10^{\prime \prime}$ \\
3 & $2+942.74$ to $3+536.51$ & 593.76 & $102^{\circ} 05^{\prime} 44^{\prime \prime}$ \\
4 & $3+646.51$ to $4+296.43$ & 609.92 & $97^{\circ} 08^{\prime} 23^{\prime \prime}$ \\
\hline
\end{tabular}

Table 3: Horizontal Curve setting out data

\begin{tabular}{ccccccc}
\hline S/N & Curve Length $(\mathrm{m})$ & Radius $(\mathrm{m})$ & $\mathrm{PC}$ & $\mathrm{PT}$ & $\Delta$ & $\operatorname{Tan}(\mathrm{m})$ \\
\hline 1 & 100 & 83.43 & $1+293.077$ & $1+393.077$ & $68^{\circ} 40^{\prime} 39^{\prime \prime}$ & 56.99 \\
2 & 100 & 73.23 & $2+842.743$ & $2+942.743$ & $28^{\circ} 11^{\prime} 28^{\prime \prime}$ & 59.54 \\
3 & 110 & 1315.23 & $3+536.505$ & $3+646.505$ & $04^{\circ} 47^{\prime} 31^{\prime \prime}$ & 55.03 \\
\hline
\end{tabular}

Note; PC is the point of curvature station, PT is the point of tangency station, $\Delta$ is the angle of deflection, Tan is the length of the tangent forming the curve. 
Table 4: Vertical Curve setting out data

\begin{tabular}{cccccccccc}
\hline S/N & Curve Length & BVCS & EVCS & BVCE & EVCE & PVI STA & PVI ELEV & AD & K \\
\hline 1 & 150 & $0+425$ & $0+575$ & 650.51 & 650.566 & $0+500$ & 649.419 & 2.984 & 50.262 \\
2 & 150 & $0+875$ & $1+025$ & 655.155 & 656.233 & $0+950$ & 656.302 & 1.622 & 92.483 \\
3 & 120 & $1+550.55$ & $1+670.55$ & 655.747 & 654.248 & $1+610.55$ & 655.69 & -2.314 & 51.851 \\
4 & 120 & $1+890$ & $2+010$ & 648.966 & 647.855 & $1+950$ & 647.522 & 2.96 & 40.538 \\
5 & 150 & $2+475$ & $2+625$ & 650.428 & 649.358 & $2+550$ & 650.844 & -2.535 & 59.175 \\
6 & 120 & $3+040$ & $3+160$ & 641.135 & 639.838 & $3+100$ & 639.946 & 1.801 & 66.642 \\
7 & 150 & $3+525$ & $3+675$ & 639.179 & 637.159 & $3+600$ & 639.043 & -2.331 & 64.344 \\
8 & 130 & $3+910$ & $4+040$ & 631.256 & 629.423 & $3+975$ & 629.624 & 2.204 & 58.984 \\
\hline
\end{tabular}

PVI STA; Point of Vertical Intersection Station, PVI ELEV; Point of Vertical Intersection Elevation, A.D; Algebraic Difference between the incoming and outgoing grade, K; Curve coefficient, BVCS; Beginning of Vertical Curve Station, BVCE; Beginning of Vertical Curve Elevation, EVCS End of Vertical Curve Station, BVCE End of Vertical Curve Elevation.

Table 5: Grades

\begin{tabular}{ccc}
\hline Tangent & Chainage & Gradient (\%) \\
\hline 1 & $0+00$ to $0+425$ & -1.455 \\
2 & $0+575$ to $0+875$ & 1.53 \\
3 & $1+025$ to $1+550.55$ & 0.092 \\
4 & $1+670.554$ to $1+890$ & -2.407 \\
5 & $2+010$ to $2+475$ & 0.554 \\
6 & $2+625$ to $3+040$ & -1.981 \\
7 & $3+160$ to $3+525$ & -0.181 \\
8 & $3+675$ to $3+910$ & -2.512 \\
9 & $4+040$ to $4+296$ & -0.308 \\
\hline
\end{tabular}

Other results obtained such as part of the plan profile and cross-section sheets are presented at the appendix section of this paper.

\subsection{Discussion}

The results shown in tables 2 to 5 are setting out data obtained from the final phase of route survey and design of the proposed road used as a case study in this research. It can be inferred from these results, that the three phases involved in route survey and design of roadways constitute a solution chain, having its final output as the design plans and setting out data for the proper construction of roadway components according to standard design specifications.

This implies that a proper implementation of the three phases of route survey and design, together with the results obtained from them, translates to a step by step solution to most of the factors that cause early deterioration of roadways, as indicated in the results shown in table 1.

\section{CONCLUSION}

Route survey and design of roadways has been successfully applied to a proposed road in this research, and the results shows that most of the causes of early road deterioration can be solved through a proper implementation of the design plans and setting out data obtained from the geometric design phase. Furthermore, the paper recommends that route survey and design should be carried out for all proposed roadways, and their construction should be made based on design plans and setting out data obtained from its geometric design phase. Further research should try to find out other methods that could be used to solve the factors of early roadway deterioration/pavement failure that were not addressed in this paper.

\section{REFERENCES}

[1] Hemamala, H., (2006). How do rural Roads benefit the poor and how. Asian Development Bank.

[2] European Road Federation (ERF), (2001). Position on the Socio-economic benefits of Roads to Society.

[3] Akinyede, J.O., (2004). Remotely sensed data for terrain classification and optimum route Selection in Nigeria: A systematic approach. AARSE, pp. $419-430$.

[4] Okigbo, N., (2012). Causes of highway failures in Nigeria. International Journal of Engineering Science and Technology (IJEST) Vol.4, No. 11, pp. $4695-4703$.

[5] Toryila, T.M., (2016). The effects of poor drainage system on road pavement: A review. 
International Journal for innovative research in multidisciplinary field. Vol.2, No. 8, pp. 216- 223.

[6] Ogundipe, O.M, (2008). Road Pavement failure caused by poor soil properties along AramokoIlesa highway. Nigerian Journal of Engineering and Applied Sciences, Vol. 3, No. 3, pp. 239 241.

[7] Oguara, T.M, (2010). A management model for road infrastructure maintenance. Book proceedings: $19^{\text {th }}$ Engineering assembly, Council for the Regulation of Engineers In Nigeria (COREN).

[8] Osuolale, O.M., Oseni A.A, and Sanni I.A, (2012). Investigation of Highway pavement Failure Along Ibadan - Iseyin Road, Oyo state, Nigeria. International Journal of Engineering Research and Technology (IJERT) Vol. 1, No. 8.

[9] Zumrawi, M.E. (2015). Investigating causes of pavement deterioration in Khartoum state,
Sudan. International Journal of Civil and Environmental Engineering Vol. 9, No. 11, pp. 1450 - 1455.

[10] Afolayan, O. D., and Abidoye, A. O., (2017). Causes of failure on Nigerian roads: A review. Journal of Advancement in Engineering and Technology, Vol. 5, pp. $1-5$.

[11] Odunfa, S. O., and Owolabi, A. O., (2018). The effect of moisture content on pavement Failure along Lagos-Ibadan express way. Federal University Lafia Journal of Science and Technology, 4(2). $43-50$.

[12] Mannering, L. and Walter, P. (1990). Principles of Highway Design and Traffic Analysis. New York: John Wiley and Sons.

[13] American Association of State Highway and Transportation Officials (AASHTO), (2001). A Policy on Geometric Design of Highways and Streets. Washington, D.C, USA.

\section{APPENDIX: SAMPLE OF PLAN, PROFILE AND CROSS-SECTIONS PRODUCED AT THE GEOMETRIC DESIGN PHASE}

PLAN (CHAINAGE: $2+750$ TO $3+175)$

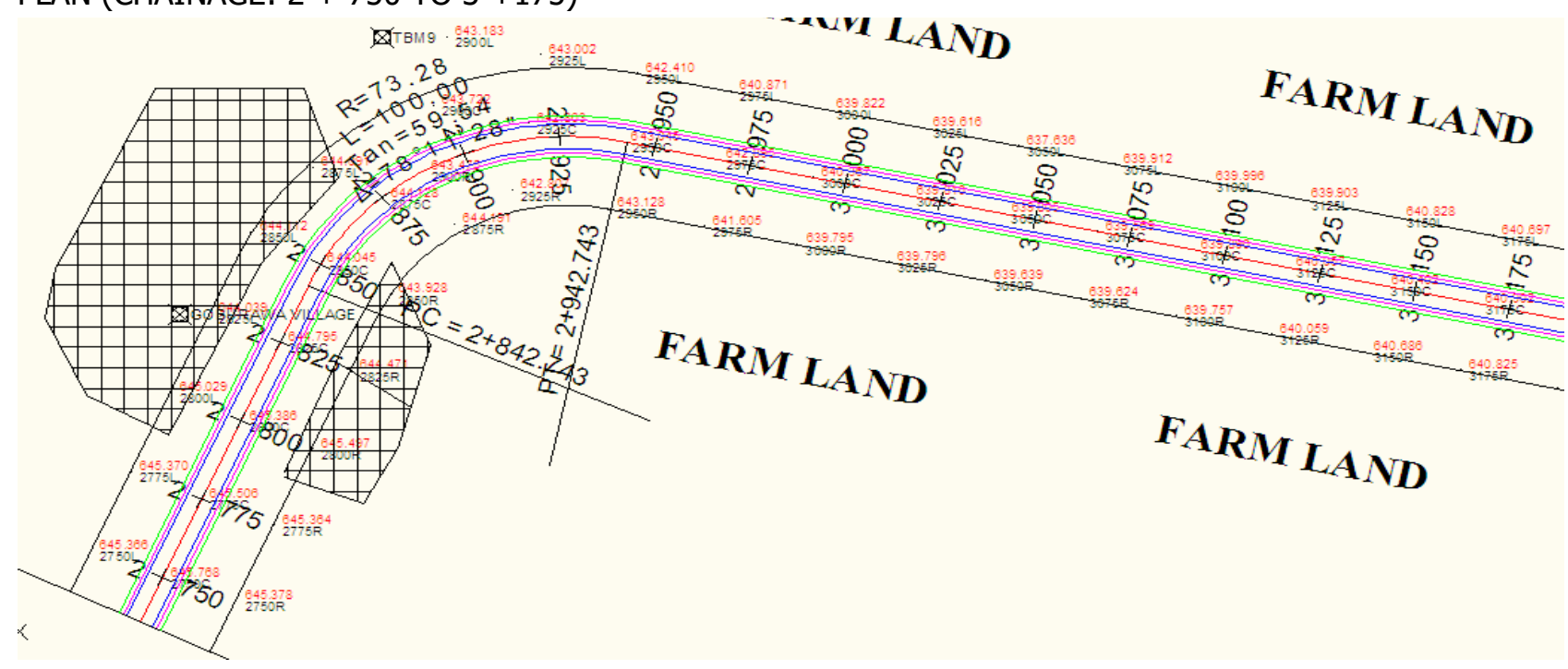

PROFILE (CHAINAGE: $2+750$ TO $3+175)$ 


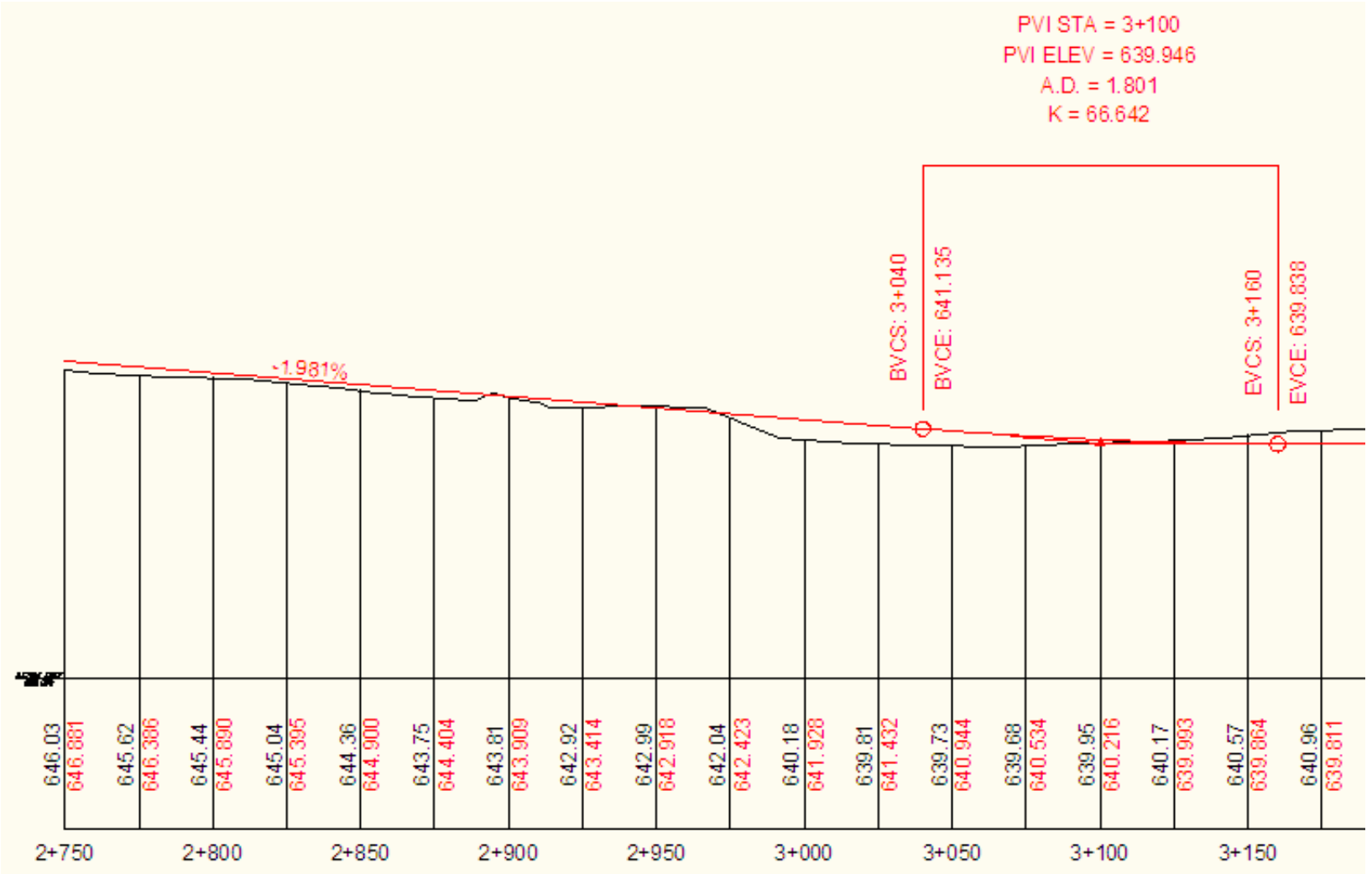

\section{LEGEND}

Bench Mark

Formation Ground

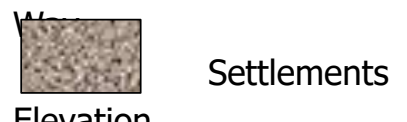

Elevation

Existing Ground

Settlements
CROSS-SECTIONS

$0+000$

658

656

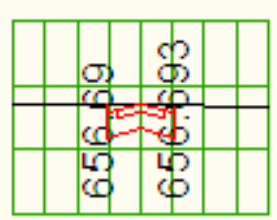

$-20-1001020$
$0+025$

658

658

656

654

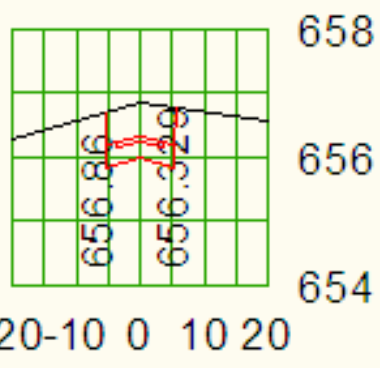

Temporary

Right of
Shoulder

Drainage

$50 \mathrm{~L}$

.655 .17 Spot 

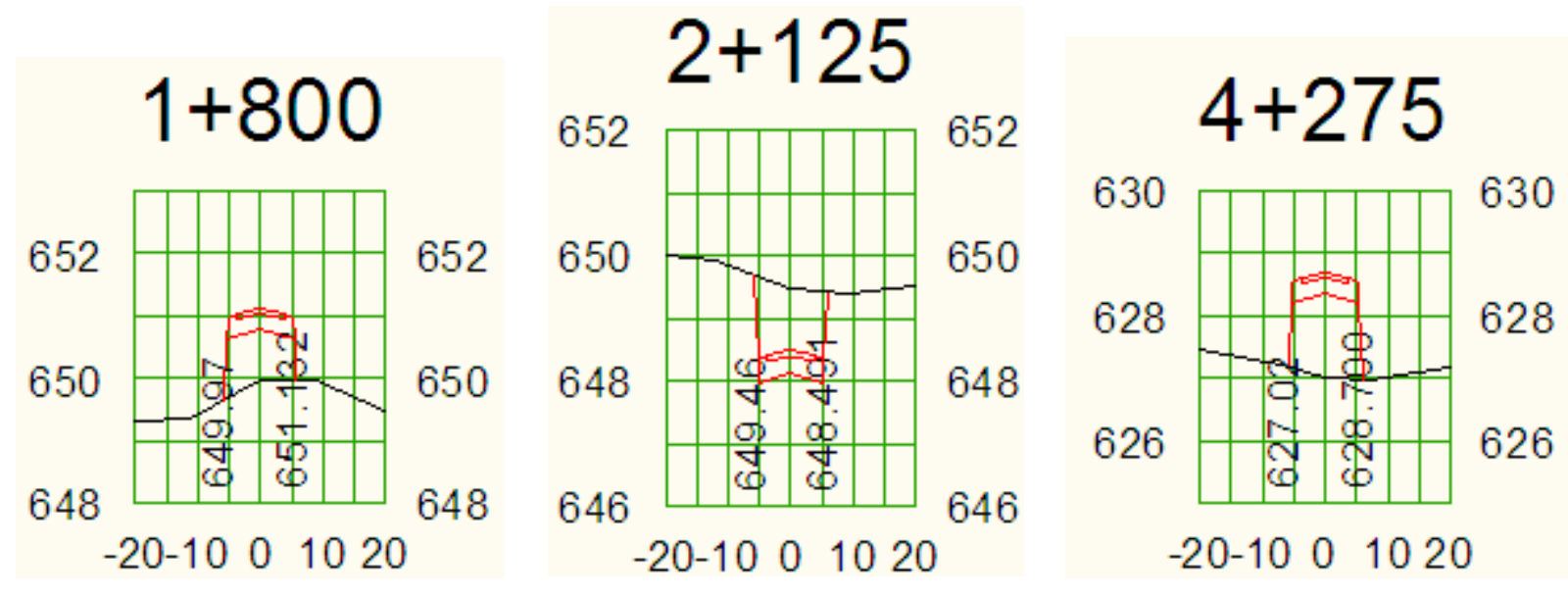

LEGEND

Cross-section Formation Ground

Cross-section Existing Ground 